\title{
Effect of nedocromil sodium on sulphur dioxide induced bronchoconstriction
}

\author{
CAROLINE M S DIXON, RICHARD W FULLER, PETER J BARNES
}

From the Department of Clinical Pharmacology, Cardiothoracic Institute, London; and the Department of Clinical Pharmacology, Royal Postgraduate Medical School, London

ABSTRACT Nedocromil sodium is a pyranoquinoline derivative that has been developed for the treatment of asthma. We report the results of a double blind randomised study of the effect of two doses of nedocromil sodium ( 2 and $4 \mathrm{mg}$ ) and matched placebo, delivered by metered dose pressure ised aerosol, on bronchoconstriction induced by sulphur dioxide in six asthmatic subjects. Nedocromil sodium had no effect on baseline lung function. The magnitude of sulphur dioxideinduced bronchoconstriction monitored by partial forced expiratory flow at $30 \%$ of reference vitaß capacity was significantly inhibited by nedocromil sodium $4 \mathrm{mg}(\mathrm{p}<0.05)$ but not by $2 \mathrm{mg}$. The maximum changes after placebo and after nedocromil $2 \mathrm{mg}$ and $4 \mathrm{mg}$ were $-44 \cdot 7,-32 \cdot 7$, and $-11.81 \mathrm{~min}^{-1}$. The area under the curve monitoring the effect over 6 minutes was significantly inhibited by both doses to the same extent, the mean changes after placebo and after nedocromil $\mathrm{mg}$ and $4 \mathrm{mg}$ being $-349 \cdot 3,-31 \cdot 2$, and $44 \cdot 61$. Dyspnoea was monitored by visual analogue scale and showed a significant reduction over 6 minutes with both doses of nedocromil. After placebo an after nedocromil $2 \mathrm{mg}$ and $4 \mathrm{mg}$ the mean maximum changes were $31.5,13.7$, and $15.7 \mathrm{~mm}$, and th 8 mean changes in area under the visual analogue scale-time curve were 289,194 , and $151 \mathrm{~mm}$.mig respectively.

Nedocromil sodium, the disodium salt of a paranoquinoline dicarboxylic acid, has been developed for the treatment of asthma. Nedocromil sodium protects against exercise induced asthma, ${ }^{1}$ antigen induced bronchoconstriction, ${ }^{2}$ antigen induced nasal obstruction, ${ }^{3}$ and bronchoconstriction caused by nonspecific stimuli. ${ }^{4}$ When administered four times daily for one month, it improves the control of bronchial asthma. ${ }^{5}$

The profile of action of nedocromil sodium is similar to that of sodium cromoglycate. Since sodium cromoglycate protects against bronchoconstrictor responses to sulphur dioxide ${ }^{6}$ we have investigated whether nedocromil sodium 2 or $4 \mathrm{mg}$ confers similar protection against sulphur dioxide induced bronchoconstriction when compared with matched placebo. It seems likely that part at least of sulphur dioxide induced bronchoconstriction depends on neural mechanisms since it is reduced by cholinergic

Address for reprint requests: Ms CMS Dixon, Department of Medicine (Respiratory), Royal Postgraduate Medical School, London W12 0HS.

Accepted 20 October 1986 antagonists, ${ }^{7}$ and in animals sulphur dioxide stimu lates afferent fibres in the airways. ${ }^{8-10}$

\section{Methods}

\section{SUBJECTS}

We studied six subjects (three of them men) with milof asthma, aged $25-58$ years. Three were ex-smokers and three non-smokers. All subjects were atopic an currently receiving $\beta_{2}$ agonists as necessary. FEV ranged from 2.8 to 4.1 litres and asthma duration from 10 to 42 years. Subjects gave informed, written consent to take part in this study, which had the् approval of the hospital ethics committee.

\section{Airway function}

Measurements of airflow and volume were made with a rolling seal spirometer (PK Morgan) linked to হूㅁ microcomputer (Hewlett Packard) (Flow analyse $\frac{\vec{\phi}}{\mathrm{\phi}}$ Collingwood Measurements, Leicester). The best op three vital capacity manoeuvres was used as the refer ence volume for subsequent measurements. The sube ject performed a forced partial expiratory manoeuvre first inhaling to end tidal inspiration and then forcible 
exhaling into the spirometer to residual volume before immediately inhaling to total lung capacity and finally exhaling to residual volume, as previously described. ${ }^{11}$ Flow $\left(1 \mathrm{~min}^{-1}\right)$ at $30 \%$ of the reference vital capacity was then computed $\left(\dot{\mathrm{V}}_{\mathbf{3 0}}\right)$.

\section{DYSPNOEA SCORE}

To quantify the subjective feeling of breathlessness a visual analogue scale was used. The subject marked an appropriate point on a $10 \mathrm{~cm}$ line labelled at one end "very breathless" and at the other end "not breathless." It was explained that the feeling of breathlessness was to include any feeling of retrosternal discomfort. The position of the subject's mark on this line was later measured in millimetres from the end of the line labelled "not breathless" and the measurement was used as the dyspnoea score in subsequent analysis. After being marked the line was obscured to prevent comparison when subsequent lines were marked.

\section{SULPHUR DIOXIDE CHALLENGE}

The sulphur dioxide challenges were performed with the subject wearing a noseclip, breathing through a mouthpiece attached to a non-rebreathing valve in a circuit designed to deliver sulphur dioxide at various concentrations at a fixed flow rate. Sulphur dioxide at $400 \mathrm{ppm}$ from a special gas mixture (British Oxygen Co, Brentford, Middlesex) was passed through a rotameter (range 0.1-1.0 $1 \mathrm{~min}^{-1}$, Fisher Controls, Croydon, Surrey) and then mixed with air from a compressor also passing through a rotameter (range 15-150 $1 \mathrm{~min}^{-1}$ ). The gases were mixed in a 25 litre chamber before inhalation via the two way valve. The exhaust gases were dispersed under water. Sulphur dioxide concentrations in the mixture were sampled proximal to the two way valve by a sulphur dioxide analyser (pulsed fluorescent sulphur dioxide analyser, Thermo Electron Corporation, Waltham, Massachusetts) connected to the sampling port by Teflon tubing. By varying the flow of sulphur dioxide from 0.125 to $0.21 \mathrm{~min}^{-1}$ and maintaining the air flow at 15 $1 \mathrm{~min}^{-1}$ different concentrations of sulphur dioxide were produced. The volume of sulphur dioxide and air inhaled was measured by a respirameter (Wright) on the input side of the mouthpiece.

\section{STUDY DESIGN}

Each subject was asked to attend the laboratory at the same time of day on five occasions, with intervals of at least five days between each visit. The subjects did not take $\beta$ adrenoceptor agonists for 12 hours and refrained from having drinks containing caffeine for four hours before each study. In preliminary studies the construction of a dose-response curve for sulphur dioxide proved not to be possible because of the development of tachyphylaxis. We therefore decided to study a single concentration of sulphur dioxide that would give a greater than $40 \%$ fall in $\dot{V}_{P_{30}}$. On the first attendance a partial dose-response curve for sulphur dioxide was constructed to determine the dose required to cause the desired degree of bronchoconstriction. This concentration and volume were then used on the three subsequent study days.

On the next three visits, after measurement of baseline $\dot{V}_{P_{30}}$, placebo or 2 or $4 \mathrm{mg}$ of nedocromil sodium was administered from matching pressurised aerosols in a double blind manner in random order. $\dot{V}_{P_{30}}$ was measured 10, 20, and 30 minutes after treatment. The visual analogue scale was recorded $30 \mathrm{~min}$ after drug inhalation. The dose of sulphur dioxide was then inhaled and $\dot{\mathrm{V}}_{30}$ and the visual analogue scale were monitored for 20 minutes or until the values returned to within $10 \%$ of baseline values. On the final day the dose of sulphur dioxide used on the drug study days was repeated to ensure that the subject's bronchial responsiveness to sulphur dioxide had not altered during the period of study.

\section{DATA ANALYSIS}

The duration of bronchoconstriction measured by $\dot{V}_{P_{30}}$ and the duration of breathlessness measured by visual analogue scale scores were calculated by measurement of the area under the $\dot{V}_{P_{30}}$-time (l) and visual analogue scale time (mm.min) curves (AUC) by the trapezoidal rule. The AUC was measured up to six minutes after sulphur dioxide inhalation, a time at which all subjects had readings on all study days. The values for $\dot{V}_{P_{30}}\left(1 \mathrm{~min}^{-1}\right)$ were analysed by analysis of variance and the differences tested by the application of the Bonferroni modification for multiple comparisons of Student's $t$ test. ${ }^{12}$ The Mann-Whitney U test was used to analyse the values for visual analogue scale. All results are expressed as mean (SD) values.

\section{Results}

No significanct difference was found between baseline values of lung function on any of the five study days. Neither 2 nor $4 \mathrm{mg}$ nedocromil sodium produced any significant change in $\dot{V}_{P_{30}}$ up to 30 minutes after administration from the values obtained before drug inhalation or after placebo.

\section{BRONCHOCONSTRICTOR RESPONSES}

The mean maximum changes in $\dot{V}_{P_{30}}$ after inhalation of sulphur dioxide are shown in table 1. There was no significant difference in the changes after exposure to sulphur dioxide on control days and after placebo. The maximum bronchoconstrictor response to sulphur dioxide was significantly attenuated $(\mathrm{p}<0.05)$ by nedocromil sodium $4 \mathrm{mg}$, but not by the $2 \mathrm{mg}$ 
Table 1 Mean (SD) maximum change in $\dot{V}_{P_{30}}$ and mean change in area under the $\dot{V} P_{30}$-time curve after administration of placebo and nedocromil sodium 2 and $4 \mathrm{mg}$ compared with control values following exposure to sulphur dioxide in six asthmatic patients

\begin{tabular}{lll}
\hline & $\begin{array}{l}\text { Maximum change } \\
\left(l \text { min }^{-1}\right)\end{array}$ & AUC $(l)$ \\
\hline Ist control & $-51.6(26.4)$ & $-553.6(399)$ \\
2nd control & $-34.0(15.9)$ & $-383.1(302)$ \\
Placebo & $-44.7(30.4)$ & $-349.3(299)$ \\
Nedocromil sodium 2 mg & $-32.7(14.0)$ & $-31.2(58)^{*}$ \\
Nedocromil sodium 4 mg & $-11.8(12.6)^{*}$ & $+44.6(139)^{*}$ \\
\hline${ }^{*}$ p $<0.05$. & & \\
$\mathrm{VP}_{30}$, flow at 30\% above reference residual volume; AUC, area \\
under the curve.
\end{tabular}

Table 2 Mean (SD) maximum change in visual analogue scale score and mean change in area under the visual analogue score time curve after treatment with placebo and nedocromil sodium 2 and $4 \mathrm{mg}$ compared with control values following exposure to sulphur dioxide in six asthmatic patients

\begin{tabular}{lll}
\hline & $\begin{array}{l}\text { Maximum change } \\
(\mathrm{mm})\end{array}$ & $\begin{array}{l}\text { AUC } \\
(\mathrm{mm} . \mathrm{min})\end{array}$ \\
\hline Ist control & $36.8(21 \cdot 1)$ & $436.6(457)$ \\
2nd control & $24 \cdot 7(10.7)$ & $352.0(390)$ \\
Placebo & $31.5(11.6)$ & $289.0(287)$ \\
Nedocromil sodium 2 mg & $13.7(11.3)^{*}$ & $194.6(278)^{*}$ \\
Nedocromil sodium 4 mg & $15.7(11.8)$ & $151.6(177)^{*}$ \\
\hline
\end{tabular}

$* \mathrm{p}<0.05$.

AUC-area under the curve.

dose, by comparison with placebo.

The duration of bronchoconstriction, measured by calculation of the area under the $\dot{V}_{P_{30}}$-time curve after sulphur dioxide inhalation, did not differ significantly between control days or after placebo (table 1). Both 2 and $4 \mathrm{mg}$ of nedocromil sodium significantly reduced the $\dot{V}_{P_{30}}$ AUC after inhalation of sulphur dioxide $(p<0.05)$.

\section{DYSPNOEA SCORE}

The mean maximum changes on the visual analogue scale after inhalation of sulphur dioxide are shown in table 2. No significant differences were observed following sulphur dioxide between control days or after placebo. A significant reduction $(p<0.05)$ was observed with $2 \mathrm{mg}$ nedocromil sodium after inhalation of sulphur dioxide. The maximum visual analogue scale score after the $4 \mathrm{mg}$ dose did not differ significantly from that after placebo as a result of one subject, in whom only the duration of response and not the maximum response was altered by the drug.

The duration of dyspnoeic symptoms, measured by calculating the area under the visual analogue seale score-time curve after sulphur dioxide inhalation did not differ significantly between control days or afte placebo (table 2 ) but was significantly reduced wifh both $2 \mathrm{mg}$ and $4 \mathrm{mg}$ nedocromil sodium $(\mathrm{p}<0.05$ 廆

\section{Discussion}

Inhaled nedocromil sodium significantly inhibited the magnitude and duration of bronchoconstriction and breathlessness after inhalation of sulphur dioxide. The $4 \mathrm{mg}$ dose had a greater protective effect than the $2 \mathrm{mg}$ dose against the maximum change in $\mathrm{V}_{P_{30}}$; bo the two doses were equally effective in limiting the duration of change in $\dot{V}_{P_{30}}$ and dyspnoea score. $\stackrel{\vec{N}}{\mathrm{~N}}$

Although some workers have been able to coip struct a three point dose-response curve for sulphut dioxide, ${ }^{13}$ like others ${ }^{14}$ we were unable to do this with our system owing to development of tachyphylaxis to sulphur dioxide. We therefore observed the effect of nedocromil sodium on the bronchoconstrictof response to a single concentration of sulphur dioxid $\vec{e}$. This protocol also allowed us to examine the effect nedocromil sodium on the duration of broos choconstriction. To detect any change in the subject's sensitivity to sulphur dioxide during the course of the study a final control day as well as a placebo day was incorporated. This showed that bronchoconstricto responses to fixed concentrations of sulphur dioxido were consistent for each subject.

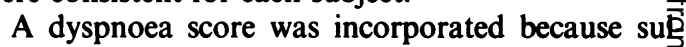
phur dioxide inhalation provoked a retrosternal diš comfort and feeling of breathlessness that appeareg to be out of proportion to the degree of bronichoconstriction when compared with other nong specific bronchial challenges such as histamine and methacholine. We therefore considered it importan to monitor the subjective assessment of dyspnoea using a visual analogue scale. ${ }^{15}$ The mechanism by which nedocromil inhibits sulphur dioxide induceed bronchoconstriction is uncertain. Nedocromil sodium inhibits the change in lung mechanics produced by antigen challenge in Ascaris sensitive monkey in vive and inhibits histamine release from mucosal mast cells in vitro with a much greater potency thag sodium cromoglycate. ${ }^{16}$ Sodium cromoglycate, hown ever, which has a profile of action similar to that of nedocromil sodium, also inhibits afferent nerve actits ity in animals, ${ }^{17}$ so possibly nedocromil sodium is acting by blocking the effect of sulphur dioxide of afferent discharge. The reduction of dyspnoea score by nedocromil sodium provides some support for an effect on afferent nerve endings.

We would like to thank Fisons PLC Pharmaceutica्यु Division and the Medical Research Council for sups porting this study. 


\section{References}

1 Shaw RJ, Kay AB. Nedocromil sodium, a mucosal and connective tissue mast cell stabiliser, inhibits exerciseinduced asthma. Br J Dis Chest 1985;79:385-9.

2 Dahl R, Pedersen B. Influence of nedocromil sodium on the dual asthmatic reaction after allergen challenge: a double-blind placebo controlled study. Eur J Respir Dis 1986;69(suppl 147):263-5.

3 Corrado OJ, Gomez E, Baldwin DL, Davies RJ. The effect of nedocromil sodium on nasal allergen [abstract]. Thorax 1986;41:246.

4 Robuschi M, Simone P, Vaghi A, Bianco S. Prevention of fog-induced bronchoconstriction by nedocromil sodium. Eur J Respir Dis 1986;69(suppl 147):289-91.

5 Lal S, Malhotra S, Gribben D, Hodder D. Nedocromil sodium: a new drug for the management of bronchial asthma. Thorax 1984;39:809-12.

6 Tan WC, Cripps E, Douglas N, Sudlow MF. Protective effect of drugs on bronconstriction induced by sulphur dioxide. Thorax 1982;37:671-6.

7 Nadel JA, Salem H, Tamplin B, Tokiwa Y. Mechanism of sulphur dioxide induced by bronchoconstriction in normal and asthmatic man. $J$ Appl Physiol 1965;20:164-7.

8 Boushey HA, Richardson PS, Widdicombe JG, Wise JCM. The response of laryngeal afferent fibres to mechanical and chemical stimuli. $J$ Physiol 1974;240:153-75.

9 Roberts AM, Hahn HL, Schulz HD, Nadel JA, Coleridge HM, Coleridge JCG. Afferent $\mathrm{C}$-fibres are responsible for the reflex airway constriction and secretion evoked by pulmonary administration of sulphur dioxide in dogs [abstract]. Physiologist 1983;25:226.

10 Widdicombe JG. Receptors in the trachea and bronchi of the cat. J Physiol 1954;123:71-104.

11 Barnes PJ, Gribbin HR, Osmanliev D, Pride NB. Partial flow-volume curves to measure bronchodilator dose response curves in normal humans. J Appl Physiol 1981;50:1193-7.

12 Wallenstein S, Zucker CI, Fleiss JL. Some statistical methods useful in circulation research. Circ Res 1980;47:1-9.

13 Sheppard D, Scott Wong W, Uehara CF, Nadel JA, Boushey HA. Lower threshold and greater bronchomotor responsiveness of asthmatic subjects to sulphur dioxide. Am Rev Respir Dis 1980;122:873-8.

14 Sheppard D, Epstein J, Bethel RA, Nadel JA, Boushey HA. Tolerance to sulphur dioxide-induced bronchoconstriction in subjects with asthma. Environ Res 1983;30:412-9.

15 Adams L, Chronos N, Lane R, Guz A. The measurement of breathlessness induced in normal subjects: individual differences. Clin Sci 1986;70:131-40.

16 Eady RP, Greenwood B, Jackson DM, Orr TSC, Wells E. The effect of nedocromil sodium and sodium cromoglycate on antigen-induced bronchoconstriction in the Ascaris-sensitive monkey. $\mathrm{Br} J$ Pharmacol 1985;85:323-5.

17 Dixon M, Jackson DM, Richards IM. The effect of sodium cromoglycate on lung irritant receptors and left ventricular cardiac receptors in the anaesthetised dog. Br J Pharmacol 1979;67:569-74. 